\title{
La entrada de Mariana de Neoburgo en el Alcázar de Madrid: un lienzo inédito
}

\author{
The entrance of Maria Anna of Neuburg in the Royal Palace \\ of Madrid: an unpublished painting
}

Recibido: 18-II-2016

Aceptado: 6-VI-2016

Resumen: A través de este artículo se da a conocer un cuadro inédito que representa La entrada de Mariana de Neoburgo en el Alcázar de Madrid. La obra es de un especial interés ya que es uno de los escasos documentos gráficos que muestra las decoraciones que con motivo de la entrada de la nueva soberana se llevaron a cabo en la Villa de Madrid en mayo de 1690.

Palabras clave: Mariana de Neoburgo, Carlos II, Entrada en la corte, Alcázar de Madrid, Villa de Madrid, Iconografía, Entradas reales, Arte efímero.

AвSTRACT: This article uncovers an unpublished painting about The entrance of Maria Anna of Neuburg in the Royal Palace of Madrid. This canvas has a special interest because it is one of the few existing documents showing the decorations created for the entrance of the new Queen in the court of Madrid, in May 1690.

Keywords: Maria Anna of Neuburg, Charles II, Entrance in the court, Royal Palace of Madrid, Villa of Madrid, Iconography, Royal entrances, Ephemeral art.

El arte efímero creado para las celebraciones regias del siglo XVII fue la máxima manifestación a la hora de acumular símbolos y metáforas y de apuntalar el pensamiento y las formas artísticas del momento en que surgió. A su vez fue también el arte más participativo, ya que hacía que el pueblo formara parte del acontecimiento artístico al tomar como escenario para su desarrollo la ciudad. Así sucedió en la entrada en la Villa de Madrid, el 22 de mayo de 1690, de la reina Mariana de Neoburgo (1667-1740), segunda esposa del rey Carlos II, donde no sólo los artífices engalanaron las calles, sino que las gentes contribuyeron ornando sus casas y presenciando el recorrido triunfal de la nueva soberana.

El despliegue de arte efímero que se hizo para la entrada de Mariana fue gran- 


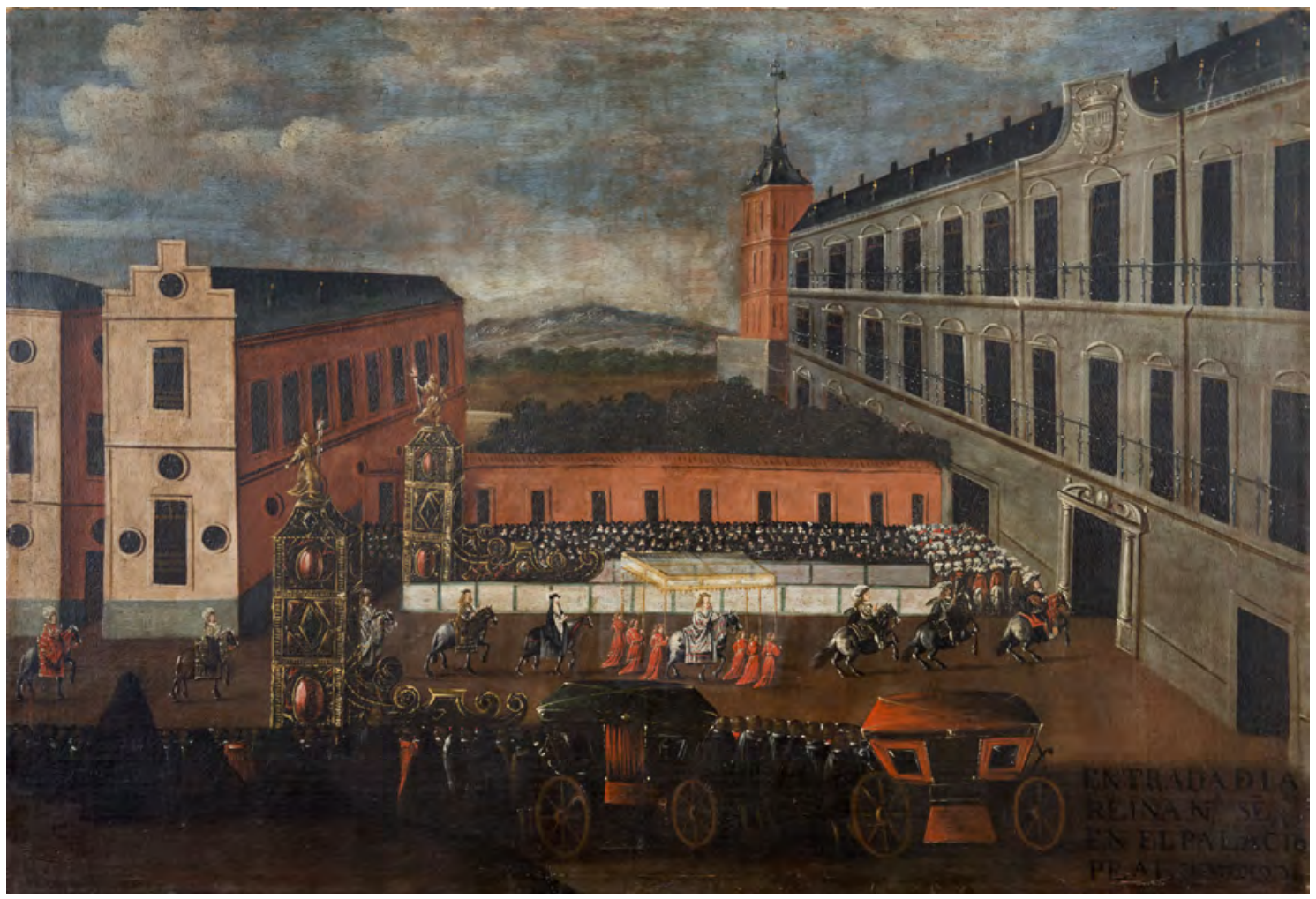

- Fig. 1. Anónimo madrileño del siglo XVII. La entrada de la reina Mariana de Neoburgo en el Alcázar de Madrid. 1690. Colección Abelló. Foto Andrés Valentín Gamazo.

de, aunque no llegó a la altura de lo acostumbrado en otras ocasiones, debido a las fuertes restricciones económicas que se impusieron. Aun así, la Villa y Corte se convirtió en un gran teatro en el que se dio cita la unión de las artes plásticas y escénicas. Hasta ahora son escasos los documentos gráficos que se conocen que muestran cómo fue esa celebración. Se cuenta, eso sí, con un dibujo preparatorio para las decoraciones de la Puerta de Guadalajara ${ }^{1}$ y con la estampa del arco triunfal que se colocó en Bruselas con motivo de la boda de Carlos II con Mariana ${ }^{2}$, por lo que es posible hacerse una idea del aspecto que pudieron tener los

${ }^{1}$ T. ZAPATA FERNÁNDEZ, “Juan Cano de Arévalo. Decoración efímera de la Puerta de Guadalajara para la entrada de Mariana de Neoburgo", en B. NAVARRETE PRIETO (dir.), I Segni nel tempo. Dibujos españoles de los Uffizi. Catálogo de la exposición, Madrid, 2016, p. 281, cat. 161.

${ }^{2}$ Biblioteca Nacional de España (en adelante BNE), INVENT/14731. R. VAN ORLEY y P. HERREBOCH, Arco levantado con motivo de la celebración de la boda de Carlos II y Mariana de Neoburgo. adornos que se realizaron en la Villa para la entrada de la reina. Asimismo también existe un buen número de dibujos de los monumentos que se levantaron con ocasión de la entrada de María Luisa de Orleans tan sólo diez años antes ${ }^{3}$. A todo ello se suma ahora el lienzo que se da a conocer y que representa un momento de La entrada triunfal de Mariana de Neoburgo en el Alcázar de Madrid (Fig. 1) ${ }^{4}$.

Tras la muerte de María Luisa de Orleans, primera consorte del monarca, el 12 de febrero de 1689, se abrió un periodo de in-

\footnotetext{
${ }^{3}$ Los dibujos para la entrada de María Luisa de Orleans han sido publicados y estudiados por T. ZAPATA FERNÁNDEZ, La entrada en la Corte de María Luisa de Orleans. Arte y Fiesta en el Madrid de Carlos II, Madrid, 2000.

${ }^{4}$ La pintura es un óleo sobre lienzo de escuela madrileña de finales del XVII y de $112 \times 164 \mathrm{~cm}$. En ella consta una inscripción en el ángulo inferior derecho que reza: "ENTRADA D LA REINA NA SE EN EL PALACIO PEAL (sic)". La obra procede de la colección de los condes de la Florida y en la actualidad se conserva en la Colección Abelló.
} 
certidumbre en la corte española. Resultaba de suma importancia encontrar pronto una nueva esposa al rey para intentar asegurar la continuidad dinástica. La elegida se anunció el 8 de marzo de 1689 al Consejo de Estado 5 . Ésta fue la condesa Palatina del Rin, Mariana de Neoburgo, quien el 10 de abril de 1690 desembarcaba en el puerto de Mugardos (Ferrol) tras una accidentada y larguísima travesía que fue objeto de varios diarios de viaje y de un romance ${ }^{6}$.

Nada más conocerse la firma de las capitulaciones matrimoniales en Madrid se creó una Junta Extraordinaria que debía de ocuparse de la organización de los festejos que, con motivo de la entrada de la nueva soberana, tendrían lugar en la Villa y Corte. La primera reunión de esa Junta tuvo lugar en diciembre de 1689, en la casa del conde de Oropesa, que actuaría como "Protector de las fiestas". Éste anunció a los presentes el deseo de Carlos II de que no se levantaran arcos triunfales en el recorrido. Las calles debían estar engalanadas, pero se debían evitar grandes gastos. La economía fue una constante a seguir desde el momento en que se produjo la boda con Mariana de Neoburgo. Para la realización del viaje se buscó la ruta que pudiera resultar más barata y el cortejo se desplazó de "incógnito" para que en los lugares por los que pasara la sobera-

\footnotetext{
${ }^{5}$ Tanto el acta de la sesión como las consultas se conservan en el Archivo Histórico Nacional (en adelante AHN), Sección Estado, Legajo 2886.

${ }^{6}$ Sobre el viaje de Mariana de Neoburgo a España, véase M. SIMAL LÓPEZ, "La llegada de Mariana de Neoburgo a España: Fiesta para una reina", Madrid: Revista de arte, geografía e historia, no 3, 2000, pp. 22-32. Tanto los diarios de viaje como el romance se conservan en la Biblioteca Nacional de España. Los primeros fueron escritos por J. M. DE LA PARRA, Viaje a España desde la Corte de Neoburgo: historia de la jornada que doña Mariana de Neoburgo hizo a España... BNE, Mss/7870 y J. ROLANDI, Diario de la jornada de la reina Mariana desde la salida de Neoburgo hasta el día de su feliz llegada al puerto del Ferrol... BNE, Mss/2061. El romance fue compuesto por F. SILVA Y RIBERA, A la misteriosa tardanza de la Reyna Reynante nuestra Señora, $q$ Dios guarde, y trayga con bien, Madrid, 1690; ejemplar consultado en la BNE, VC/1045/6.
}

na no tuvieran que hacerle entrada pública. Asimismo, no se le habilitó en Flandes casa acompañante, para reducir gastos. En España se tomaron otra serie de medidas en pos del ahorro, como la de prohibir el uso de oro y plata en los bordados de vestidos y colgaduras. Se pretendía con todas estas prevenciones no hacer los dispendios que con ocasión de la primera boda de Carlos II se realizaron. Para conseguir el objetivo de economizar, se pidió a los presidentes de los gremios más importantes, joyeros, plateros y mercaderes de sedas, que se encargaran del adorno de las calles en algunos tramos. Del mismo modo, se visitó a los responsables de las iglesias, conventos y hospitales situados en el recorrido de la comitiva, para pedirles que se ocuparan de engalanar las fachadas de sus edificios.

Posteriormente se citó a los artistas que debían intervenir en el festejo y se examinaron y aprobaron sus proyectos. Entre los contratados estaban José Caudí, Francisco Ignacio Ruiz de la Iglesia, Antonio Palomino y Teodoro Ardemans ${ }^{7}$. Este último fue el encargado de dirigir los diseños para la entrada, ya que Claudio Coello rehusó el ofrecimiento de participar ${ }^{8}$, al estar en esos momentos ocupado en encargos de mayor relevancia para la Corte, como la realización de La Sagrada Forma del Real Monasterio de San Lorenzo de El Escorial ${ }^{9}$. No obstante, Coello retrató al poco de su llegada a la nueva soberana, tal y como recoge Palomino: "Y habiéndose celebrado el segundo matrimonio del Señor Carlos Segundo en el año de 1690, retrató también Claudio [Coello] à la Reina nuestra Señora Doña Ma-

\footnotetext{
${ }^{7}$ Véase T. ZAPATA FERNÁNDEZ, “La Entrada de la reina María Ana de Neoburgo en Madrid (1690). Una decoración efímera de Palomino y de Ruiz de la Iglesia", Anuario del Departamento de Historia y Teoría del Arte, Vols. IX-X, 1997-1998, pp. 257-275.

${ }^{8}$ ÍDEM, Arquitecturas efimeras y festivas en la corte de Carlos II: las entradas reales, Tesis Doctoral defendida en la Universidad Autónoma de Madrid, 1991, pp. 789 y siguientes.
}

${ }^{9}$ E. J. SULLIVAN, Claudio Coello y la pintura barroca madrileña, Madrid, 1989, pp. 109-135. 


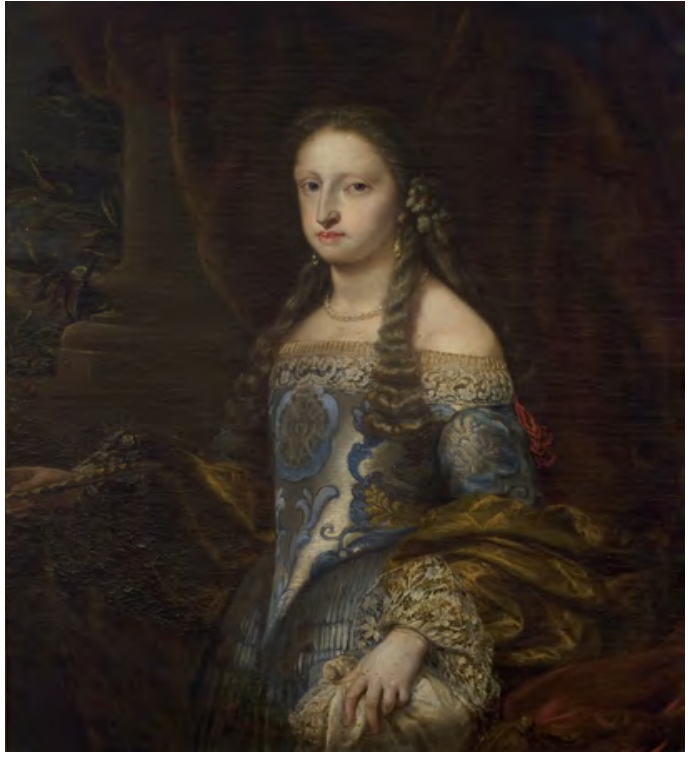

- Fig. 2. Claudio Coello. Mariana de Neoburgo. ca. 1690. Fundación Casa Ducal Medina Sidonia. Foto Fundación Casa Ducal de Medina Sidonia.

ría Ana de Neoburg"10. Este primer retrato al que se refiere Palomino es seguramente la fantástica efigie de dos tercios de la soberana que se encuentra en la colección Fundación Casa Medina Sidonia (Sanlúcar de Barrameda), la cual sirvió de modelo, posteriormente, para diversas versiones por parte de su taller (Fig. 2) ${ }^{11}$.

Todo se tenía en cuenta, incluso el estado de las calles. Así, un acuerdo del Ayuntamiento decía que se debían limpiar de basuras los caminos y adecentar de "manera que no haya mal paso y se pueda pasar con facilidad"12. Pero el Concejo del Ayuntamiento no solo se encargó de esos preparati-

${ }^{10} \mathrm{~A}$. PALOMINO DE CASTRO Y VELASCO, El Museo pictórico y escala óptica, 1724, Ed. de Madrid, 1947, p. 1064.

${ }^{11}$ Fundación Casa Ducal de Medina Sidonia, óleo sobre lienzo, $106 \times 86 \mathrm{~cm}$. Sobre éste y otros retratos de Mariana de Neoburgo, véase G. MARTÍNEZ LEIVA, "El exilio de la reina viuda Mariana de Neoburgo y la configuración de un nuevo retrato áulico", Jornadas de Arte e Iconografía Carlos II y el Arte de su Tiempo, Madrid, 2013, pp. 219-256 y D. GARCÍA CUETO, Claudio Coello, pintor (16421693), Madrid, 2016, pp. 181-183, fig. 103.

${ }^{12}$ D. VALGOMA Y DÍEZ-VARELA, Entradas en Madrid de Reinas de la Casa de Austria, Madrid, 1966, pp. 15-16.

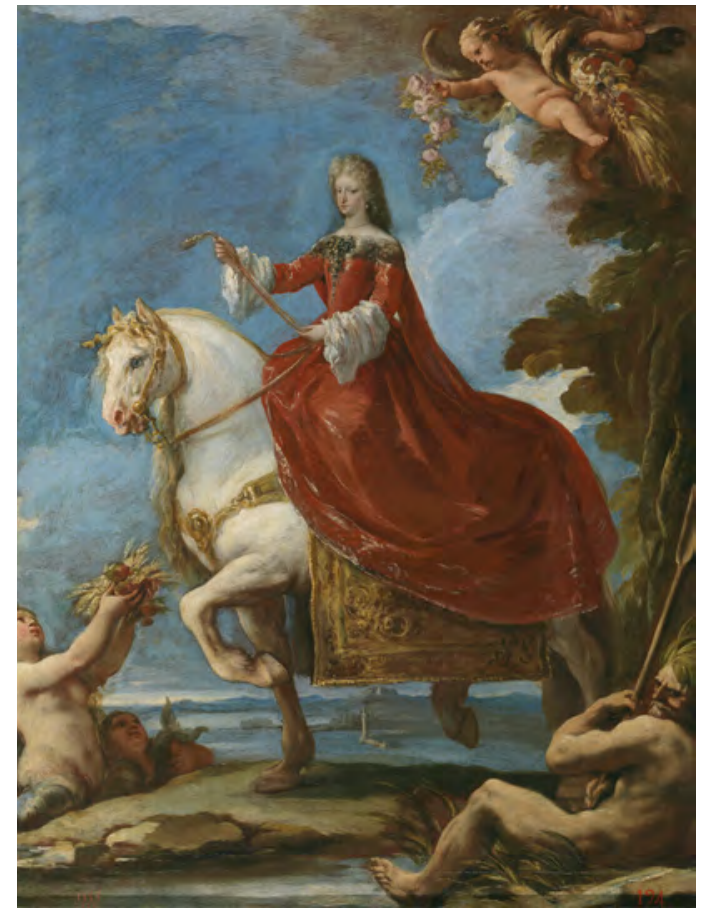

- Fig. 3. Luca Giordano. Mariana de Neoburgo, reina de España, a caballo. ca. 1693-1694. Museo Nacional del Prado. Foto Museo Nacional del Prado.

vos, sino también de organizar el cortejo de hombres ilustres que debían de acompañar a la reina a su llegada a Madrid. El Ayuntamiento requería para ser digno de ir al lado de la reina a personas principales e hijosdalgos. Hay que destacar que todos los gastos de la entrada pública de la reina corrieron a cargo del Municipio, como era tradicional.

Tras un largo y accidentado viaje la reina llegaba a El Pardo el 15 de mayo de 1690, y al día siguiente entraba en Madrid y tomaba alojamiento en el palacio del Buen Retiro. Para esa ocasión la soberana lució "vestida de color de fuego, con preciosa bordadura de talco, y montera de lo mismo, guarnecida de diamantes y amatistas, gargantilla de perlas..."13. Esa misma indumentaria es la representada en los bocetos realizados por Luca Giordano de Mariana de Neoburgo a caballo (Fig. 3) ${ }^{14}$ y que forman pareja con sen-

${ }^{13}$ J. M. DE LA PARRA, Op. cit., fol. 81r.

${ }^{14}$ Museo Nacional del Prado (en adelante MNP), óleos sobre lienzo, $\mathrm{n}^{\mathrm{o}}$ invs. 198 y 2763, 81,2 x 61,4 cm y $80 \times 62 \mathrm{~cm}$. En la colección Granados se conserva otro 
dos retratos del rey también a caballo ${ }^{15}$. Estos bocetos se realizarían con la idea de llevar a cabo composiciones de grandes dimensiones que celebraran la llegada de la nueva soberana ${ }^{16}$, algo que ya había sucedido con motivo de la entrada de María Luisa de Orleans y que quedó plasmado en los lienzos de los monarcas a caballo realizados por Francisco Rizi que se encuentran en el Ayuntamiento de Toledo ${ }^{17}$. De hecho, la iconografía que se muestra en los bocetos alude a uno de los temas principales en la entrada de la soberana: la fertilidad que estaría representada por náyades y ángeles niños que sostienen una cornucopia llena de flores y frutos.

Tras la llegada de la reina al Retiro, Carlos II decidió que la recepción pública en la Villa se hiciese a caballo ${ }^{18}$ y tuviese lugar el día 22 de mayo: "He resuelto que el lunes, veintidos deste mes, sea la entrada pública de la Reyna en Madrid; y asi os mando deis las órdenes convenientes para que, por la parte que os toca, se disponga que esté prevenido en este sitio para las tres y media de la tarde todo lo necesario para la función"19.

El camino que había de recorrer la soberana era el comprendido entre el palacio del Buen Retiro y el Alcázar, un eje definido

apunte más de Giordano con la misma composición y dimensiones (óleo sobre lienzo, 82 × $62 \mathrm{~cm}$ ), aunque resulta más somero. De los tres el de mayor calidad es el proveniente de la colección real (MNP, $\mathrm{n}^{\circ}$ inv. 198). Véase en $\mathrm{G}$. MARTÍNEZ LEIVA y A. RODRÍGUEZ REBOLLO (dirs.), Semblantes. Colección Granados. Catálogo de la exposición, Segovia, 2011, cat. 8, pp. 48-49.

${ }^{15}$ MNP, óleos sobre lienzo, $\mathrm{n}^{\mathrm{o}}$ invs. 197 y $2762,81,1 \mathrm{x}$ $60,3 \mathrm{~cm}$ y $80 \times 62 \mathrm{~cm}$.

${ }^{16}$ Véase T. ZAPATA FERN ÁNDEZ, Arquitectura efimeras..., pp. 115-117 y A. PASCUAL CHENEL, El retrato de Estado durante el reinado de Carlos II. Imagen y propaganda, Madrid, 2010, p. 580.

${ }^{17}$ Ayuntamiento de Toledo, óleos sobre lienzo, 344 x $312,5 \mathrm{~cm}$. cada uno.

18 “...he resuelto que la entrada pública de la Reyna en esta corte se haga a cavallo, arreglándose a la Pragmática", Archivo General de Palacio (en adelante AGP), Sección Histórica, Caja 72, s. fol.

${ }^{19}$ Ibídem, Caja 48, s. fol. ya desde el siglo XV gracias a la importancia del acceso a la ciudad desde el Este, en lugar del camino de Alcalá, y que quedará afianzado después de la construcción del palacio del Buen Retiro, lugar donde las reinas esperaban alojadas para realizar su entrada ceremonial en la Villa ${ }^{20}$. A la una de la tarde de aquel día salieron treinta y ocho miembros capitulares de la Villa, bellamente vestidos y con sus caballos noblemente enjaezados, acompañados por timbales, trompetas, maceros y alguaciles, hacia el palacio del Buen Retiro $^{21}$.

A las cuatro y media de la tarde montó Mariana de Neoburgo sobre un precioso caballo blanco y a ella le siguió un extenso cortejo de grandes, nobles, damas, representantes de las Órdenes Militares, músicos y guardias. Partiendo de la puerta del palacio del Buen Retiro, creada en 1680 por Melchor de Bueras con motivo de la entrada de María Luisa de Orleans y modificada para la ocasión con una inscripción conmemorando la entrada de Mariana de Neoburgo (Fig. 4), se llegaba a la Puerta del Arco, donde se procedió a hacerle entrega de las llaves de la Villa. Esta puerta estaba toda guarnecida con jeroglíficos y emblemas. A cargo de su diseño estuvo el maestro arquitecto Pedro

\footnotetext{
${ }^{20}$ Sobre este tema véase M.A. TOAJAS ROGER, “La ciudad transfigurada. Ideas y proyectos para obras efímeras en Madrid (S. XVII-XIX)", en Las propuestas para un Madrid soñado: de Teixeira a Castro. Catálogo de la exposición, Madrid, 1992, p. 111.

${ }^{21}$ Para conocer el itinerario y decoraciones que se dispusieron para la entrada en la corte de la reina Mariana de Neoburgo se conservan dos folletos impresos, de escasas páginas, que se publicaron el día de la fiesta a modo de crónica: F. FABRO BREMUDAN, Bosquejo de la Triunfante magnifica, y suntuosissima entrada, que en esta Catolica Corte executó a veinte y dos de mayo del presente año de 1690, Nuestra Augustissima Reyna, y Señora Doña Maria-Ana, Princesa Palatina del Rhin..., (12 hojas). Real Biblioteca (en adelante RB). Signatura III/6582 (4) y L.A. BEDMAR Y B ALDIVIA, La Real Entrada en esta Corte y magnífico triunfo de la Reyna... Doña María-Ana Sophia de Babiera y Neoburg..., Madrid, 1690. BNE, Z/66971. Sin embargo, el libro con una descripción más amplia y detallada de lo acontecido, que debía ir acompañado con grabados de las decoraciones, no pudo ser llevado a cabo por motivos económicos.
} 


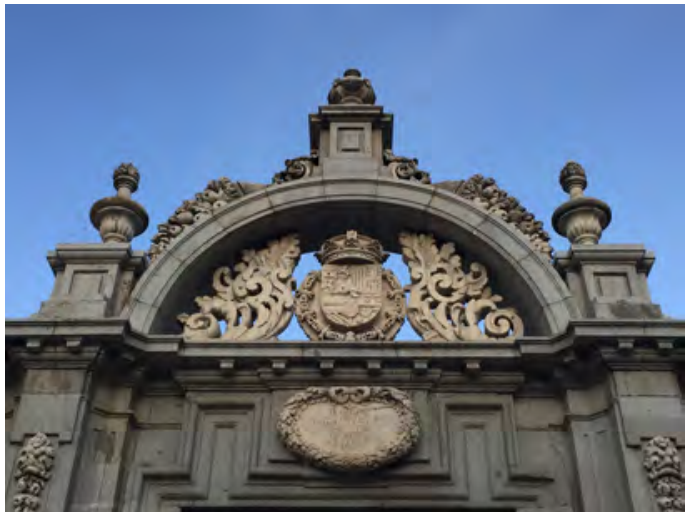

- Fig. 4. Melchor de Bueras. Antigua puerta de entrada al Palacio del Buen Retiro. 1680, modificada en 1689. Foto de la autora.

de Ávila ${ }^{22}$. Pasado este punto se subía por la actual Carrera de San Jerónimo hasta el Convento de Nuestra Señora de la Victoria. A ambos lados de la vía se colgaron una serie de pinturas de famosos artistas italianos y madrileños. Continuando por ese camino se llegaba a la Lonja de Nuestra Señora de la Soledad, en la cual se creó un jardín ficticio regado por diferentes fuentes, que pretendían sorprender con sus saltos de agua. Poco después se arribaba a la Iglesia del Buen Suceso, donde se albergaba una imagen de la virgen considerada milagrosa ${ }^{23}$, cuya fachada estaba adornada con las mejores telas y tapices.

Tras un breve periplo se llegaba el Real Convento de San Felipe ${ }^{24}$, para cuyo adorno el Duque del Arco prestó treinta y seis

${ }^{22} \mathrm{~V}$. TOVAR MARTÍN, “El arquitecto madrileño José Arroyo, autor de "Festejo y loa en honor de Mariana de Neoburgo", Anales del Instituto de Estudios Madrileños, $\mathrm{n}^{\mathrm{o}}$ 17, 1980, p. 290.

${ }^{23}$ J. RUIZ DE ALTABLE, Historia de la Milagrosa Imagen de Nuestra Señora del Buen Suceso, Madrid, 1641.

${ }^{24}$ La lonja del convento amenazaba ruina, por lo que se decidió vestir por completo el lugar para que tuviera la decencia adecuada a la solemnidad que iba a acaecer en sus alrededores. Sobre los complejos jeroglíficos que adornaron el sitio véase T. ZAPATA FERNÁNDEZ, "Los jeroglíficos del convento de San Felipe el Real de la Corte para la entrada de María Ana de Neoburgo", en G. REDONDO VEINTEMILLAS, A. MONTANER FRUTOS y M. C. GARCÍA LÓPEZ (coords.), Actas del I Congreso Internacional de Emblemática General, Madrid, 2004, Vol. III, pp. 1847-1874. reposteros y el Cardenal Portocarrero diez cuadros de diferentes géneros de famosos pintores de Roma. Enfrente de San Felipe las fachadas fueron engalanadas de telas, jeroglíficos y retratos de varones ilustres. Pocos pasos más adelante se situaba la casa del conde de Oñate, la cual estaba completamente vestida, y desde la que el Gran Maestre de la Orden Teutónica, Carlos II y Mariana de Austria disfrutaron del espectáculo antes de que estos dos últimos se unieran al cortejo.

Toda la calle Mayor estaba ornada con lienzos creados ex profeso ${ }^{25}$. En la bocacalle de San Ginés se situó un tablado, para los miembros del Consejo de Indias, con estatuas y jeroglíficos, y en los Portales de los Rasilleros se colocaron los retratos de los reyes de Castilla hasta Carlos II.

El tablado del Consejo de Órdenes estaba en la calle de la Amargura, decorado con multitud de espejos y estatuas y rematado por la estatua ecuestre de Santiago. Muy cercano a esta calle se encontraba el portal de los Pellejeros, en el cual se veía una demostración de gran originalidad, ya que se habían vestido una serie de animales con sus mismas pieles. Pasado éste, en la bocacalle de la plaza de Herradores, se colocó el tablado para el Consejo de Hacienda, que era del mismo arte que los anteriormente referidos. Se llegaba poco después a la Puerta de Guadalajara, para cuya decoración los mercaderes de sedas eligieron una traza de Juan Cano de Arévalo consistente en una galería, a modo de logia de treinta arcos, quince a cada lado, que flanqueaba un trozo de la calle Mayor. Ésta estaba decorada con jeroglíficos, figuras femeninas y alusiones a la Casa de Austria y de Baviera ${ }^{26}$. Para la entrada de

${ }^{25}$ En ellos se representaban: “todas las Plaças del Reyno de Ungria, restauradas por las Imperiales Armas desde el año 1683. Y porque no huviesse mas que desear en tan grata representacion, estavan colocados encima de las Plaças, los retratos de los Euroes [sic]; que se han inmortalizado en los afanes de tan santa, y vitoriosa Guerra, con Elogios adequados al merito de cada uno". Véase F. FABRO BREMUDAN, Op. cit., p. 5.

${ }^{26}$ Para la realización de este conjunto se conserva un dibujo preparatorio en la Galleria degli Uffizi, $\mathrm{n}^{\mathrm{o}}$ inv. 
María Luisa de Orleans en la Villa también se levantó una galería, la denominada Galería de los Reinos, que iba desde la nueva portada del Buen Retiro hasta el arco del Prado, creando así un paseo palacial de unos doscientos sesenta metros de largo. Esta espectacular galería estaba decorada con pinturas de fuentes, vegetación, ninfas y estatuas femeninas que personificaban los veinticuatro reinos que componían la monarquía española. Tanto las dimensiones como el porte de esta decoración efímera fue mucho más ambiciosa que la realizada para el recibimiento de Mariana de Neoburgo, tal y como puede observarse en el grabado de Claudio Coello que de ésta se conserva ${ }^{27}$.

Unos metros más adelante estaba el lugar de la calle Mayor donde se distribuían todas las platerías, con sus escaparates relucientes por multitud de joyas de oro y plata, y seguidamente se llegaba a la plazuela de la Villa o de San Salvador, donde se situó uno de los ornatos más importantes. Las trazas de éste fueron dadas por Antonio Palomino, quien lo ejecutó en colaboración con Francisco Ignacio Ruiz de la Iglesia. El proyecto consistía en un gran edificio que incluía en su interior la fuente de la plazuela de la Vi$11 a^{28}$.

El recorrido llegaba a su término en la plaza del Alcázar de Madrid en donde se situaban: "dos sobervios Carros Triunfales de admirable invencion, con diferentes Figuras

10539S. Publicado por T. ZAPATA FERNÁNDEZ, “Juan Cano de Arévalo ...", p. 281, cat. 161.

27 BNE, $\mathrm{n}^{\circ}$ inv. INVENT/70860. En T. ZAPATA FERNÁNDEZ, ÍDEM, “Claudio Coello: dibujos festivos", Archivo Español de Arte, no 263, 1993, pp. 275-277 e ÍDEM, La entrada en la Corte de María Luisa de Orleans..., pp. 81-98.

${ }^{28}$ Una descripción precisa del arco que se creó fue realizada por el propio Palomino y la recogió en su obra más célebre, El Museo Pictórico y escala óptica. Véase A. PALOMINO DE CASTRO Y VELASCO, Op. cit., pp. 657-664. El contrato para la realización de la obra con el Ayuntamiento y un detallado análisis de esta decoración lo ofrece T. ZAPATA FERNÁNDEZ, “La Entrada de la reina María Ana de Neoburgo en Madrid...", pp. 260-270 y 273. doradas, y otras de color natural. Ocupavanlos, vestidos de ricas galas los Representantes, además de otros distribuydos en varios parages de la calle, y en otras partes muchos Danzantes" $^{29}$.

El cuadro que aquí se analiza representa justamente ese momento del final del recorrido en el que la reina está a punto de entrar en el Alcázar de Madrid (véase Fig. 1). El escenario donde se desarrolla la acción es la fachada sur o principal del palacio, la cual se muestra parcialmente. En ella se ve su discreta portada rematada por el escudo de armas de Felipe IV y el paño correspondiente de ésta hasta la Torre Dorada. El Alcázar, con sus varios niveles exteriores hacia el sur, su portada levemente destacada, sus cubiertas de pizarra con buhardillas y sus torres flanqueando las esquinas, presenta un aspecto semejante al que puede observarse en la Maqueta del edificio realizada por Juan Gómez de Mora hacia $1630^{30}$. Junto a la Torre Dorada se refleja el Jardín de los Emperadores, al que se accedía desde una estancia en la parte baja de esa torre. El jardín se representa frondoso, con árboles frutales, aunque tanto en la maqueta de Gómez de Mora como en las crónicas de la época se le describe más bien como un espacio renacentista decorado con numerosas esculturas $^{31}$. El jardín quedaba separado de la plaza de palacio por un muro bajo con arquería rematado en teja. Éste fue construido por José del Olmo hacia 1675 y aquí se representa de forma tan somera que ni siquiera figura la baranda metálica con bustos de emperadores romanos que lo remataba ${ }^{32}$. En

${ }^{29}$ F. FABRO BREMUDAN, Op. cit., p. 8.

${ }^{30} \mathrm{~J}$. GÓMEZ DE MORA, Maqueta del Alcázar de Madrid, ca. 1630. Museo de Historia de Madrid, nº inv. 3133.

31 “Cerca della [de la Torre Dorada] está un jardín adornado de fuentes, y estatuas de Emperadores Romanos, y la del gran Carlos Quinto". G. GONZÁLEZ DÁVILA, Teatro de las grandezas de la Villa de Madrid..., Madrid, 1623, p. 310.

32 Esta galería puede apreciarse perfectamente en el lienzo de 1677 de escuela madrileña Vista del cortejo de Carlos II en el Alcázar de Madrid, que se conserva en la co- 


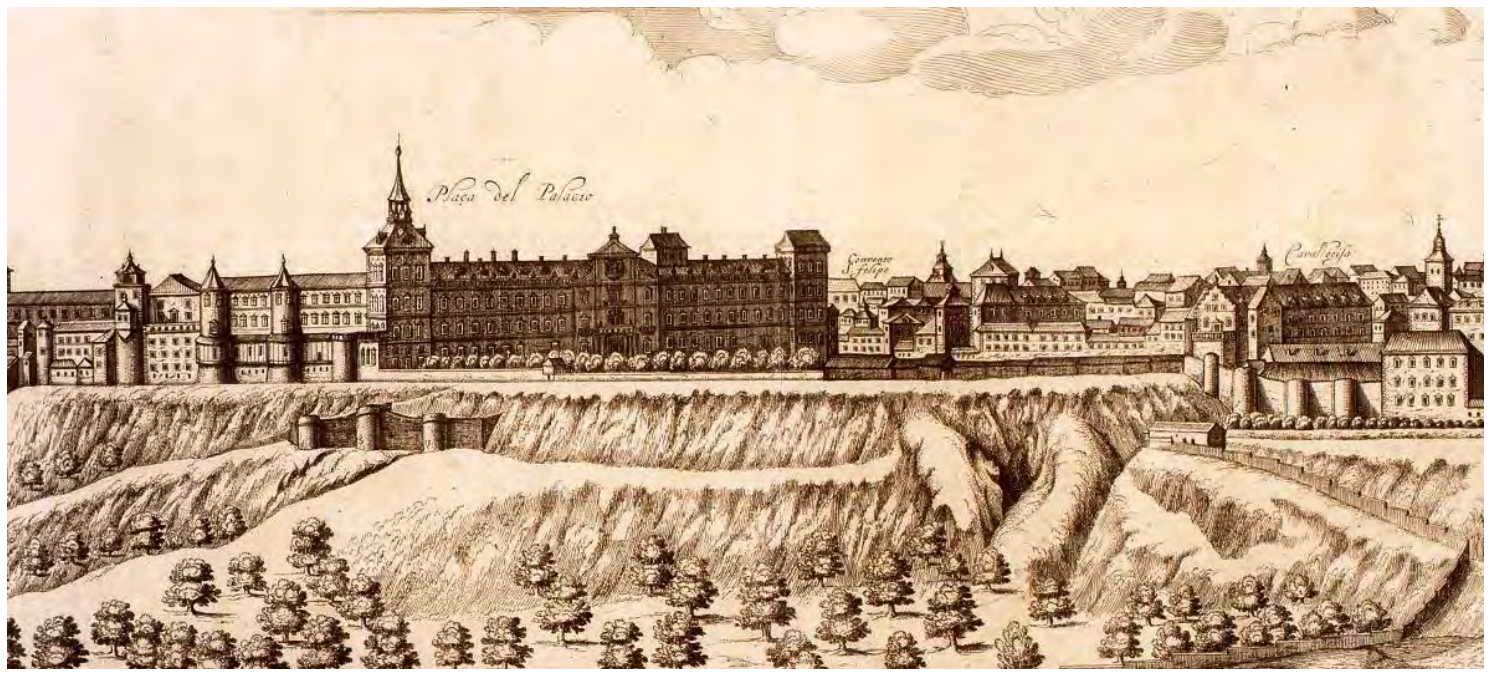

- Fig. 5. Julius Milheuseur. Vista de Madrid (detalle). ca. 1665. Museo de Historia de Madrid. Foto de la autora.

el lado izquierdo de la composición se sitúa un edificio de planta rectangular con cubierta escalonada, correspondiente a las Caballerizas Reales y a la Armería Real creadas por Gaspar de Vega a instancia del rey Felipe II. Levantado en el extremo opuesto de la plaza meridional del palacio, carecía de una comunicación directa con la residencia regia. Este lienzo supone un documento excepcional para conocer el aspecto de las caballerizas de Felipe II ya que normalmente no figuran en las representaciones del Alcázar, aunque sí son visibles en representaciones de la Villa como la de Julius Milheuseur (Fig. 5) ${ }^{33}$. Esto se debe a que estaban mucho más alejadas del palacio de lo que figuran en el óleo, ya que se situaban en lo que hoy en día es la cripta neorrománica de la Catedral de la Almudena. Sin embargo, el artista no creó la suficiente profundidad y perspectiva en la obra para dar la sensación de una mayor distancia entre los edificios.

En lo referente a los personajes, éstos representan un rico cortejo que se dirige hacia

lección Abelló (óleo sobre lienzo, 74,8 x 112,8cm). Véase F.V. GARÍN LLOMBART (dir.), Colección Abelló. Catálogo de la exposición, Madrid, 2014, pp. 23 y 164, cat. 4.

${ }^{33}$ J. MILHEUSEUR, Vista de Madrid, ca. 1665, Museo de Historia de Madrid, $n^{\circ}$ inv. 21129. En ésta se observa con claridad la cubierta escalonada del edificio de las Caballerizas Reales. la entrada del Alcázar ${ }^{34}$. La reina Mariana de Neoburgo centra la composición y va precedida por tres jinetes lujosamente vestidos, que serían los caballerizos. Ella figura subida sobre un caballo gustosamente enjaezado y luce para el acontecimiento de su entrada: “... un precioso vestido de tela blanca de joyas, primorosamente vordado; sombrero de plumas, y en su vuelta la Perla Margarita [sic], también llevó su Mgd el Real Anillo del Diamante grande, por cuya calidad logra la estimación de único; así mismo de inapreciable valor" ${ }^{\prime \prime 3}$.

Este vestido fue ejecutado por las costureras del oficio de Guardajoyas de la rei$\mathrm{na}^{36}$. Mariana lo acompañó con las dos joyas de los Austrias más representativas, la perla Peregrina y el Estanque, el gran diamante cuadrado que era colocado en muy diversas

${ }^{34} \mathrm{El}$ cortejo para las entradas de las soberanas estaba perfectamente protocolizado, tal y como muestra la "Planta de acompañamiento de las Reinas en la Corte" que se encuentra en el AGP, Sección Histórica, Caja $51 / 148$.

\section{${ }^{35}$ J. M. DE LA PARRA, Op. cit., fol. 87r.}

36 "Vestido de raso blanco, bordado, cuaxado de sedas blancas y entorchados blancos... costó 8.001 reales de vellón". Las sedas para el vestido fueron proporcionadas por Pedro Fernández de Recas, mercader de sedas y de telas de SS. MM. AGP, Sección Reinados, Carlos II, Caja 177/1 y 2. 


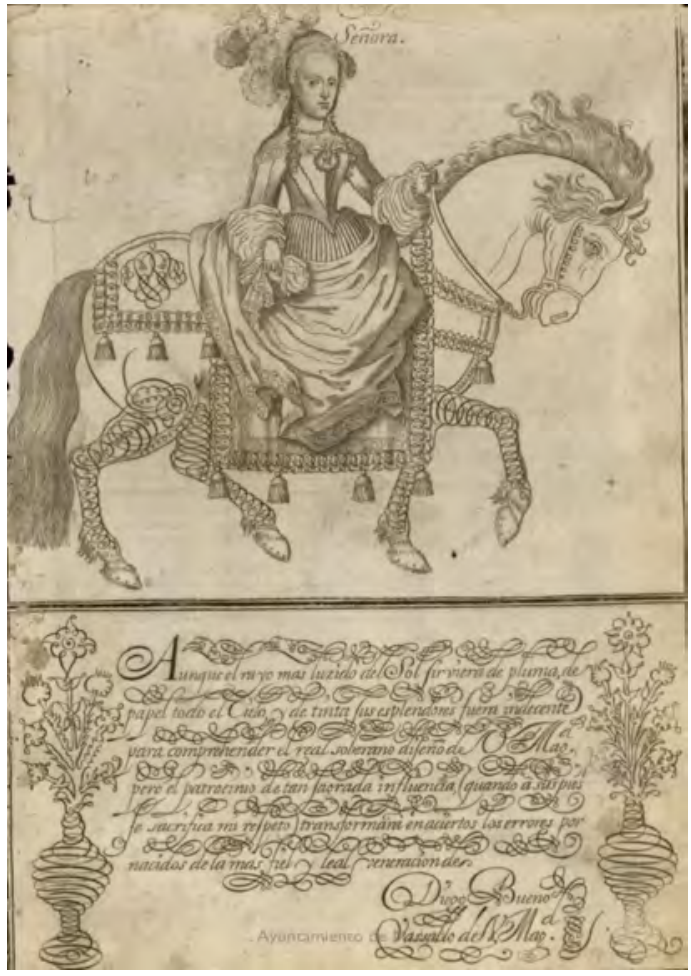

- Fig. 6. D. BUENO, Arte de leer con elegancia..., Zaragoza, 1700, p. 33. Foto Ayuntamiento de Madrid.

monturas; y por el joyel rico de diamantes que su marido le regaló con motivo del enla$\mathrm{ce}^{37}$. La imagen de la reina debió ser tan majestuosa que quedó prendida en la retina de quienes contemplaron su cortejo, tanto que cuando en 1700 Diego Bueno publicó su tercera edición del Arte de leer con elegancia... ${ }^{38}$, éste agradeció el patrocinio de la edición a la soberana y le dedicó un bellísimo dibujo, que hasta ahora había pasado inadvertido, y en el que la representaba tal cual había hecho su entrada en Madrid diez años atrás (Fig. 6).

${ }^{37}$ Sobre esta pieza véase el artículo de J. R. SÁNCHEZ DEL PERAL, "Jan Van Kessel II y la 'Joya Grande' de Mariana de Neoburgo: Consideraciones sobre el retrato portátil en la época de Carlos II", Reales Sitios, no 150, octubre-diciembre del 2001, pp. 65-74.

${ }^{38}$ D. BUENO, Arte de leer con elegancia las escrituras mas general, y comunes en Europa..., Zaragoza, 1700, p. 33. La primera edición de este manual se publicó en 1690 bajo el nombre de Arte nuevo de enseñar a leer, escrivir, y contar Príncipes y señores (BNE, R/5233) pero en él no figura el grabado al que aquí hacemos referencia.
En el lienzo la soberana va situada bajo un palio blanco sujetado por seis regidores del Ayuntamiento ${ }^{39}$, detrás de ella se encontraba, en primer lugar, la reina Mariana de Austria, con su indumentaria de viuda, y posteriormente el rey Carlos II. Tras el monarca irían, según las relaciones de la época, el Marqués de los Balbases, como Caballerizo Mayor de la reina, y la Duquesa de Alburquerque, su Camarera Mayor.

Enmarcando el cortejo de personajes que se dirigían al Alcázar se ubicaron dos grandes estructuras efímeras torreadas, de varios pisos de altura, a modo de carros triunfales, coronados por sendas figuras llevando antorchas. Éstas representarían a Himeneo, el cual porta la antorcha encendida como símbolo de amor y purificación. El dios griego del matrimonio era un elemento iconográfico que no faltaba en los festejos de las bodas regias y, por ello, también se integraba en la decoración del cuerpo central del arco levantado por Palomino en la plazuela del Salvador. Asimismo, es conocido que también formó parte de las arquitecturas que se levantaron con ocasión de la boda de Mariana de Austria con Felipe IV, decorando un arco levantado en la entrada de la plaza de Palacio y haciendo pareja con una estatua de Mercurio, -de esta figura de $\mathrm{Hi}$ meneo se conserva un bello dibujo de Francisco Rizi en la Biblioteca Nacional (Fig. 7) ${ }^{40}$-; y también integró los ornatos en la entrada de María Luisa de Orleans, situándose una escultura de éste en el Arco de Santa María,

${ }^{39}$ La descripción del palio que se elaboró para la entrada de María Luisa de Orleans coincide con el que en este lienzo se muestra, por lo que es muy probable que se utilizara el mismo para economizar. Para la completa descripción de éste véase T. ZAPATA FERNÁNDEZ, La entrada en la Corte de María Luisa de Orleans..., p. 52.

${ }^{40}$ BNE, DIB/13/2/41. F. RIZI, Himeneo, 1649. Dibujo a pluma y pincel a tinta parda y aguada gris. Véase $C$. SÁENZ DE MIERA SANTOS, "Entrada triunfal de la Reina Mariana de Austria en Madrid el día 15 de noviembre de 1649", Anales del Instituto de Estudios Madrileños, no 23, 1986, pp. 167-174 y T. ZAPATA FERNÁNDEZ, "La entrada en la Corte de Mariana de Austria. Fuentes literarias e iconográficas", en Fuentes y modelos de la pintura barroca madrileña, Madrid, 2008, pp. 105-204. 


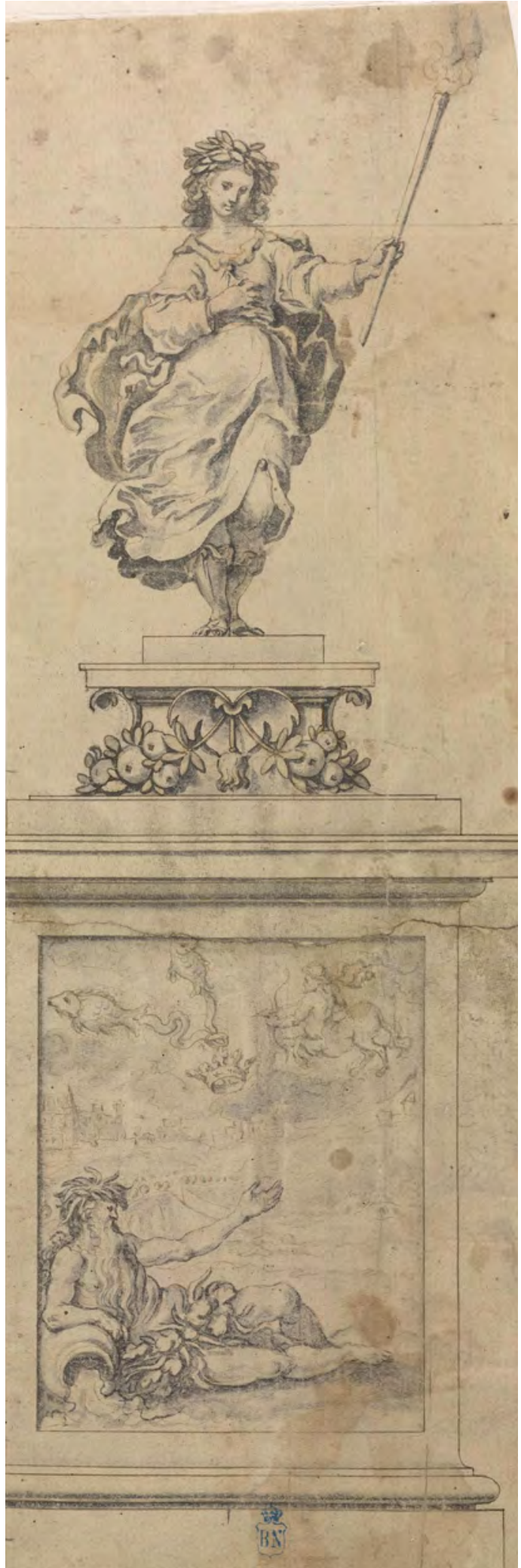

- Fig. 7. Francisco Rizi. Himeneo. 1649. BNE, DIB/13/2/41. Foto Biblioteca Nacional de España. el último del recorrido antes de embocar la plaza del Alcázar de Madrid ${ }^{41}$.

Los carros estaban delimitados por vallas de madera, detrás de las cuales se situaba una serie de personajes que, si se atiende a lo acontecido en la entrada de María Luisa de Orleans, serían músicos y cantantes que entonarían alabanzas en honor a la reina ${ }^{42}$. Finalmente, en primer plano, tras la valla más cercana al Real Convento de San Gil, figuraba una serie de Gentes del pueblo, tales como dueñas cubiertas con sus largas capas negras quienes, aunque ocupando un lugar muy secundario, también serían partícipes del acontecimiento.

La plaza del Alcázar de Madrid se convirtió así en un escenario en el que las arquitecturas efímeras enmascaraban y daban una imagen ideal del entorno, ocultando la realidad cotidiana ${ }^{43}$. El carácter temporal de acontecimientos como las entradas de las soberanas permitía que se desplegara la imaginación de artistas y literatos y que éstos buscaran con sus obras sorprender al público. La simulación, el juego y el artificio ideado por estos creadores barrocos logró que con materiales de bajo costo económico, como madera, pasta de papel o tela, se crearan arcos triunfales, carrozas o galerías, que junto a la colocación de lienzos, tapices, plantas y fuentes transformaron los espacios reales en puros decorados teatrales. Una suerte de $L a$ vida es sueño de Calderón para que la gente pudiera huir de su realidad cotidiana ${ }^{44}$.

Unas decoraciones semejantes a las representadas en el lienzo debieron ser las que

${ }^{41}$ T. ZAPATA FERNÁNDEZ, La entrada en la Corte de María Luisa de Orleans..., p. 174.

${ }^{42}$ Ibídem, p. 193.

${ }^{43}$ Véase A. BONET CORREA, "La arquitectura efímera del barroco en España", en F. CHECA CREMADES (coord.), Arte barroco e ideal clásico: aspectos del arte cortesano de la segunda mitad del siglo XVII, Roma, 2004, p. 25.

${ }^{44}$ Sobre este tema en concreto véase T. FERRER VALLS, "La fiesta en el Siglo de Oro: en los márgenes de la ilusión teatral", en Teatro y fiesta del Siglo de Oro en tierras europeas de los Austrias. Catálogo de la exposición, Madrid, 2003, pp. 27-37. 
se levantaron en la plaza del Alcázar en la entrada de las soberanas que precedieron en el trono a Mariana de Neoburgo. Para la llegada de María Luisa de Orleans se sabe que se situaron dos carros triunfales con adornos "de pasta, niños, Fama, vichas, pabos reales y otras cosas" ${ }^{\prime 4}$, en cuyo interior iban mujeres representando a ninfas y gracias. Asimismo el camino que debían de recorrer los carros estaba señalado con vallas de madera decoradas con caballos y escudos de Armas del Rey y de la Villa, en el caso de María Luisa de Orleans, y esmaltadas de azul con adornos de mascarones y fruteros, en la entrada de Mariana de Austria ${ }^{46}$. Llama la atención, sin embargo, en lo representado en el cuadro de La entrada de Mariana de Neoburgo la austeridad de las decoraciones, tanto de los carros como de las vallas que delimitaban el camino. Asimismo, tampoco figuran reposteros, tapices o guirnaldas $\mathrm{ni}$ en la fachada del Alcázar ni en el edificio de las caballerizas y de la armería, algo que consta sí sucedió en época de Mariana de Austria y María Luisa de Orleans. Es posible que esta cierta sencillez o "deslucimiento" esté causado por el poco detalle del lienzo y su extraña perspectiva, a la que ya se ha hecho referencia, pero es evidente que la falta de liquidez en esos momentos y la escasa ilusión con la que Carlos II accedía nuevamente al matrimonio fueron decisivos para economizar al máximo y que al final la entrada resultara un tanto comedida, palideciendo lo representado en el cuadro frente a los majestuosos dibujos que se conservan de las decoraciones levantadas para las de sus dos antecesoras ${ }^{47}$.

${ }^{45}$ T. ZAPATA FERNÁNDEZ, La entrada en la Corte de María Luisa de Orléans, pp. 192 y 315.

${ }^{46}$ Ibídem, p. 193.

${ }^{47}$ De hecho, como ya se ha indicado, el libro detallando lo acontecido que debía publicarse como justificación de la ceremonia, rememoración de lo acaecido y elogio y ensalzamiento hacia la soberana, nunca llegó a ser editado por falta de dinero. Véase nota 21.
No obstante, aunque el recibimiento que se le dispensó a Mariana de Neoburgo no fue de un fasto excesivo, fue una muestra más del gusto de la sociedad barroca por el divertimento, lo artificioso y maravilloso.

Asimismo constituyó una ocasión más para hacer propaganda del poder de una monarquía que, pese a que estaba en estado de emergencia tras la pérdida de territorios, las dificultades económicas y la incapacidad de dar un sucesor por parte de Carlos II, quería seguir ofreciendo a sus ciudadanos la ilusión de una realidad mejorada.

En palabras de Virginia Tovar, "la fiesta se utilizó como una pantalla distractiva entre el ciudadano y su problemática histórica... como el mejor recurso para iluminar la vida, para alegrar sus días, alejándolo de la mediocridad de su entorno" ${ }^{\prime 4}$. En definitiva, el despliegue de arte efímero con motivo de la entrada de la reina sirvió así tanto de evasión para el pueblo como de muestra de la distinción con la que se trataba a la realeza ${ }^{49}$. Algo, esto último, considerado natural e incluso exigible en el siglo XVII: “...cúan preciso es para el respeto, algún exterior culto, que distinga a los Reyes de los demás hombres: la destreza estará en saber hazerle lugar para la veneración, sin desmedro de los vasallos, y componer la Magestad de su Trono, la pompa de su Palacio, lo magnífico de su Familia, con embidia de todos y sin racional quexa de ninguno" ${ }^{\prime 50}$.

${ }^{48}$ V. TOVAR MARTÍN, El barroco efímero y la fiesta popular, la entrada triunfal en el Madrid del siglo XVII, Madrid, 1985 , p. 7.

${ }^{49}$ Tapié dijo al hablar sobre el barroco y el arte efímero, "ha exaltado la riqueza y la gloria, pero no ha desdeñado a los humildes, pues ha tratado de comprender sus miserias y suavizarlas". V. L. TAPIÉ, Barroco y clasicismo, Madrid, 1978, p. 382.

${ }^{50}$ A. NÚÑEZ DE CASTRO, Libro histórico politico; sólo Madrid es Corte y el cortesano en Madrid, Madrid, 1675, fol. 194r. 